\title{
EL SOFT LAW Y LA COSA INTERPRETADA COMO PARTE DE PROCESOS DE CREACIÓN NORMATIVA EN EL SISTEMA INTERAMERICANO DE DERECHOS HUMANOS
}

\author{
THE SOFT LAW AND THE RES INTERPRETATA AS PART OF NORMATIVE CREATION \\ PROCESSES IN THE INTER-AMERICAN HUMAN RIGHTS SYSTEM
}

\author{
Joel Isaac Rangel Agüeros ${ }^{1}$ \\ DOI: $\underline{\text { https://doi.org/10.5377//rd.v40i1.8915 }}$
}

\section{RESUMEN:}

La evolución de las ideas o valores sociales y el desarrollo de las diversas materias del conocimiento humano han tenido, como una de sus consecuencias, la proliferación de los instrumentos conocidos como soft law, los cuales, pese a su carencia de efectos vinculantes, parecen haber encontrado un camino (imperfecto e inacabadotodavía) que permite que su contenido tenga la posibilidad de cristalizarse como un estándar de protección de derechos a través de nuevas formas de producción normativa.

PALABRAS CLAVE: Soft law; procesos de creación normativa; surgimiento de derechos y obligaciones internacionales; Corte Interamericana de Derechos Humanos; competencia consultiva; competencia contenciosa; cosa interpretada;estándar mínimo de protección; efectos vinculantes; efectos erga omnes.

\begin{abstract}
:
The evolution of the ideas or social values and the development of the different matters of human knowledge have had, as one of its consequences, the proliferation of the instruments known as soft law, which, despite their lack of binding effects, they seem to have found a path (imperfect and still unfinished) that allows their content to have the possibility of crystallizing as a standard of protection of rights through new forms of normative production.
\end{abstract}

KEY WORDS: Soft law; normative creation processes; emergence of international rights and obligations; InterAmerican Court of Human Rights; advisory jurisdiction; contentious competence; res intepretata; minimum standard of protection; binding effects; erga omnes effects.

Fecha de recepción: 31 de agosto del 2019

Fecha de aprobación: 30 de octubre del 2019

\footnotetext{
${ }^{1}$ Secretario de Estudio y Cuenta de la Suprema Corte de Justicia de la Nación (México), Maestro en Derecho Fiscal por la Universidad Panamericana (México) en Derecho Fiscal por la Universidad Panamericana (México) Secretario de Tribunal Colegiado. Secretario y Actuario de Juzgado de Distrito. Subadministrador de lo Contencioso "F" de Grandes Contribuyentes, en el Servicio de Administración Tributaria (México). Email: JIRangelA@mail.scin.gob.mx
} 


\section{INTRODUCCIÓN}

Tradicionalmente se ha considerado que las normas que componen el orden jurídico deben tener su origen en estructuras o fuentes formales, que se encuentren rígidamente ordenadas, de preferencia a través de una estructura piramidal, sistema a través del cual se pretende que los fenómenos sociales hallen soluciones en disposiciones de carácter positivo que se imponen unilateral y verticalmente.

En otras palabras, la producción de normas comúnmente se monopoliza por órganos legislativos o autoridades administrativas, quienes comúnmente responden a meras agendas de carácter político e incluso partidario, por lo cual emiten disposiciones que imponen a la sociedad (de arriba hacia abajo) sin tomar en consideración que la constante relación entre la realidad y el Derecho debe ajustarse no solo a la velocidad de las circunstancias de hecho y al dinamismo de la evolución social, sino también al deseo de participación de diversos sectores, ya sea por un sentido de reivindicación o justicia, o bien por tratarse de temas o aspectos de la realidad que requieren una regulación altamente técnica o especializada.

En ese contexto, han surgido nuevas formas de analizar y conceptualizar la creación de normas jurídicas, una de ellas se refiere al denominado derecho suave o soft law, así como a distintos tópicos que de este concepto se derivan.

La presente investigación, pretende explorar si es posible que el soft law, pese a no ser considerado como una fuente tradicional del derecho, puede ser incorporado (al menos su contenido) al orden jurídico como un estándar mínimo de protección de derechos humanos, el cual pudiera, además, gozar de un carácter no solo vinculante, sino también erga omnes, particularmente bajo el sistema interamericano de protección de los derechos de referencia.

Para ello, estimo necesario hacer referencia a la definición que la doctrina autorizada ha realizado del fenómeno del soft law, así como de la forma en que se considera que puede incorporarse al orden jurídico, para con ello analizar el sistema interamericano de derechos humanos, en especial, las facultades de la Corte Interamericana (acotándolo a la contenciosa y la consultiva) y determinar con ello las posibilidades de que la interpretación de las normas que establecen y garantizan derechos humanos, funcionen como procesos de producción de normas.

\section{METODOLOGÍA}

En el desarrollo del presente trabajo investigativo se empleó el método dogmático jurídico, para lo cual se estableció primeramente la definición que la doctrina autorizada ha realizado del fenómeno del soft law y de los diversos procesos a través de los cuáles pueden incorporarse al orden jurídico. Partiendo de tales premisas, se elige como ámbito de estudio el sistema interamericano de derechos humanos, específicamente las facultades contenciosa y consultiva de la Corte Interamericana.

Hecho lo anterior, se realiza el análisis correspondiente para determinar las posibilidades de que la interpretación de las normas que establecen y garantizan derechos humanos, cuando es llevada a cabo por órganos facultados para ello, conforme a la estructura orgánica y ámbitos competenciales establecidos por la Convención Americana, pueden adquirir el estatus de estándar mínimo de protección, con carácter vinculante y general, es decir, si es probable afirmar que se están en presencia de un proceso de producción de normas.

\section{EL SOFT LAW COMO INICIO DE PROCESOS DE CREACIÓN NORMATIVA}

La expresión soft law (derecho suave, blando o flexible) ha sido motivo de diversas discusiones doctrinales que confrontan posturas distintas, como las consistentes en si las palabras que la componen resultan una contradicción en sí mismas (porque una norma jurídica -en su acepción clásicano puede ser suave, en el sentido de no generar efectos vinculantes) $)^{2}$ frente a las que estiman que

${ }^{2}$ GALIANA SAURA, Ángeles, "La expansión del Derecho flexible y 
precisamente esa ambigüedad permite la virtud de incluir fenómenos jurídicos diversos; o las posiciones en el sentido de que los actos o instrumentos que engloba tal concepto no pueden ser considerados estrictamente como derecho, al no emanar de alguna de las fuentes formales tradicionales (comúnmente referidas al derecho internacional) frente a las que opinan que las constantes transformaciones del orden normativo internacional generan la insuficiencia de tal sistema de fuentes para explicar la producción normativa actual, por lo que se debe evolucionar hacia un modelo teórico que suponga la existencia de un sistema internacional escalonado y continuo en el cual existe una normatividad variable. ${ }^{3}$

Además, tal expresión no se ha empleado con un significado uniforme, pues suele referirse a instrumentos heterogéneos que tienen en común dos elementos: no son jurídicamente vinculantes (por una multitud de factores) y gozan de relevancia jurídica; mientras que, por otro lado, la expresión de mérito puede emplearse respecto de instrumentos, ya sean jurídicamente vinculantes (legal soft law) o no lo sean (instrumentos entonces, doblemente soft). Independientemente de ello, se aprecia que la expresión se aplica a instrumentos cuya juridicidad es dudosa o cuya fuerza vinculante se cuestiona”. ${ }^{4}$

Sin embargo, tal discordancia de posturas no es obstáculo para que se formulen definiciones que intentan delimitar el concepto de referencia, de las cuales incluso pueden advertirse elementos comunes.

La teoría clásica suele acudir al artículo $38 \mathrm{del}$ Estatuto de la Corte Internacional de Justicia como el fundamento o referencia autorizada que prevé las fuentes del derecho internacional, señalando como tales a las convenciones internacionales, la costumbre internacional, los principios generales de derecho, así como las decisiones judiciales y la doctrina ampliamente reconocida.

su incidencia en la producción normativa", publicado en Anuario de Filosofía del Derecho, 2016 (XXXII), pp. 297-322.

${ }^{3}$ DEL TORO HUERTA, Mauricio Iván: "El fenómeno del soft law y las nuevas perspectivas del Derecho Internacional", publicado en Anuario Mexicano de Derecho Internacional, vol. VI, 2006, pp. 518 y ss.

${ }^{4}$ MAZUELOS BELLIDO, Ángeles: "Soft law: ¿mucho ruido y pocas nueces?", publicado en Revista Electrónica de Estudios Internacionales (REEI), No 8, 2004, p. 2.
Pese a ello, las dinámicas diversas y complejas del derecho internacional han generado la producción de una multiplicidad de documentos e instrumentos jurídicos que, en principio, no pueden ser ubicados dentro de las categorías antes referidas, además de que predomina una falta de claridad sobre el carácter normativo, vinculante y jerárquico de dichos documentos en el orden jurídico internacional.

Para Castro Novoa, tales documentos son los que han sido denominados como soft law, los cuales se caracterizan en que sus procesos de formación no son los de las fuentes tradicionales; generalmente son emitidos por organismos internacionales, o tienen su origen en acuerdos no vinculantes entre estados, o en el trabajo de organizaciones internacionales no estatales o de grupos de especialistas en una materia específica; asimismo, están dotados de una relevancia jurídica -lo cual no implica que sean vinculantesque les concede una vocación de carácter normativo. ${ }^{5}$

Otros autores estiman que el término soft law busca describir la existencia de fenómenos jurídicos caracterizados por no tener fuerza vinculante, aunque no son carentes de efectos jurídicos o al menos de tener cierta relevancia jurídica. En efecto, Del Toro Huerta considera que el término es usualmente empleado por la doctrina para describir principios, reglas, estándares o directrices y envuelve una amplia gama de documentos, como resoluciones de organizaciones internacionales, recomendaciones e informes adoptados por organismos internacionales o dentro de conferencias internacionales; programas de acción; textos de tratados que no han entrado en vigor, declaraciones interpretativas de determinados tratados o convenios; disposiciones programáticas o non-self-executing; acuerdos no normativos, acuerdos políticos o gentlemen's agreement, códigos de conducta, directrices, estándares, entre otros. ${ }^{6}$

${ }^{5}$ CASTRO NOVOA, Luis Manuel, Fragmentación, soft law y sistema de fuentes del Derecho Internacional de los Derechos Humanos, Bogotá, Universidad Nacional de Colombia, 2014, p.97.

${ }^{6}$ DEL TORO HUERTA, Mauricio Iván, op. cit. supra, nota 2, p. 534. 
Por otra parte, Garrido Gómez expone que el soft law suele tratarse en contraste con el hard law, el cual implica que hay obligaciones formales y materiales, así como mecanismos de cumplimiento, como sanciones legales y económicas que se imponen unilateral o multilateralmente. De ahí que los requisitos del hard law deben ser la precisión, obligatoriedad y delegación, mientras que el soft law puede describirse como "nuevos arreglos de gobernanza", que si bien tienen una naturaleza normativa, no poseen obligatoriedad, uniformidad, justiciabilidad, ni sanciones $\mathrm{y} / \mathrm{o}$ autoridades que los exijan. ${ }^{7}$

Galiana Saura ${ }^{8}$ señala que la denominación de $s o f t$ law suele emplearse para referirse a todos aquellos actos que carecen de eficacia normativa y que son dictados por organismos internacionales, ya tengan éstos poder normativo ocarezcan de él, con diversa denominación, como resoluciones, recomendaciones, guías, códigos o estándares de conducta.

Se trata de normas que carecen de eficacia directa y erga omnes, así como de la oponibilidad propia de las normasjurídicas del hard law; sin embargo, poseen un alcance jurídico que ha de ser definido en cada caso, dado que son herramientas técnicas con las que se pretende influir en el Derecho positivo de los Estados, estableciendo los principios informadores de las distintas regulaciones nacionales, detallando el tratamiento posible de los diversos aspectos de un tema o realizando otra serie de consideraciones.

Además, no tienen en común un estándar de intensidad por lo que a su alcance jurídico respecta, pero coinciden en que están dirigidas y tienen como efecto, influir en la conducta de los Estados, las organizaciones internacionales y los individuos, sin contener, por sí solas, derechos y obligaciones jurídicas internacionales.

De lo anterior, puede advertirse que la doctrina generalmente define al soft law como la serie de actos o instrumentos jurídicos (contenidos en una amplia gama de documentos) que carecen de un carácter

\footnotetext{
${ }^{7}$ GARRIDO GÓMEZ, Ma. Isabel, El soft law como fuente del Derecho Extranacional, Madrid, Dykinson, S.L., 2017, pp.55 y ss.

${ }^{8}$ GALIANA SAURA, Ángeles,op. cit. supra, nota 1, p. 305.
}

vinculante (en el sentido de que su cumplimiento no puede ser exigido ni sancionado en forma directa ni erga omnes) en los cuales se establecen principios, reglas, estándares, directrices o comentarios, que constituyen herramientas de carácter técnico, con las que se pretende influir en el derecho positivo, o en la conducta, de los Estados, las organizaciones (privadas o públicas) y sus individuos, además de que gozan de efectos jurídicos y de un carácter o vocación abiertamente normativa.

Cabe destacar que generalmente son emitidos por organismos internacionales, ${ }^{9}$ organizaciones internacionales no estatales o de grupos de especialistas en una materia específica, por lo que sus procesos de formación suelen ser diversos a las fuentes formales tradicionales.

Asimismo, sus efectos jurídicos, legitimidad y obligatoriedad no se basan en la facultad reguladora de los estados, sino en la participación voluntaria en su construcción, operación y continuación, lo cual no lleva al extremo de una separación absoluta de la potestad estatal, ya que comúnmente los emisores de las normas de soft law son parte de organismos $\mathrm{u}$ organizaciones internacionales a las cuales se adhieren los estados como resultado de procesos de globalización, regionalización, así como de búsqueda de objetivos comunes (protección y garantía de derechos; desarrollo económico; aspectos de carácter técnico -tributarios o de telecomunicaciones-); etcétera.

Por ende, los efectos jurídicos y normativos de las normas de soft law dependerán de cada caso concreto y variarán del propio contexto normativo correspondiente a su proceso de emisión.

De las definiciones doctrinales antes referidas, se aprecia que el fenómeno del soft law suele ser analizado tomando como referencia la teoría de las fuentes formales del derecho internacional; la dicotomía entre sus características y las del hard law (sobre todo respecto de si son normas vinculantes o no)o incluso desde una perspectiva de graduación continua del ${ }_{9}^{9}$ Aunque también se estiman como soft law, los acuerdos no vinculantes entre estados. 
orden jurídico, que va desde el "no derecho", pasando por el soft law, el hard law y el derecho consuetudinario (en el cual también se considera el derecho de gentes o ius cogens).

Pese a ello, tales posturas doctrinales se han matizado hacia vislumbrar o dilucidar los temas inherentes al soft law desde un punto de vista de procesos de formación de normas y de creación de derechos y obligaciones internacionales. ${ }^{10}$

En efecto, la teoría sobre procesos de creación normativa implica reconocer que el derecho emerge o cambia a partir del surgimiento y desarrollo de nuevas ideas y valores sociales, que se modifican y evolucionan conforme lo hacen los diversos campos de la actividad y el conocimiento humanos, avances que reclaman un reconocimiento formal y una protección jurídica más inmediata dentro del orden jurídico internacional y doméstico.

Asimismo, tales procesos de creación normativa y las materias o problemas sobre los que se pronuncian, demandan procedimientos de incorporación más rápidos y eficaces, sin que sea necesario pasar por todo el tiempo que conllevaría una negociación formal de un tratado o acuerdo internacional.

Pero tal idea no debe ser llevada al extremo de una fragmentación o relativización del derecho internacional, que podría tener como resultado incertidumbre jurídica ante una difuminación de las normas que regulan el nacimiento de obligaciones y reconocimiento de derechos; por lo contrario, la teoría de procesos de creación normativa debe tomar como premisa que los tratados y acuerdos internacionales, así como el derecho consuetudinario, siguen siendo la principal forma de generación de esos derechos y obligaciones.

Así, con base en esa premisa, la teoría de mérito también implica que las nuevas ideas o valores sociales y el desarrollo de las diversas materias del conocimiento humano (muchas de ellas eminentemente técnicas) encuentren un nuevo ámbito de integración al orden

\footnotetext{
${ }^{10}$ DEL TORO HUERTA, Mauricio Iván, op. cit. supra, nota 2, p. 530.
}

jurídico, con la posibilidad de que su carácter no vinculante transite hacia criterios o estándares que sean obligatorios e incluso erga omnes.

En ese orden de ideas, los principios, reglas, estándares, directrices o comentarios de soft law, atendiendo a los procesos de creación normativa previstos en un orden, contexto o sistema jurídico determinado (comúnmente regulados en tratados o convenios internacionales) pueden conmutar su carácter no vinculante hacia normas, criterios o estándares obligatorios que generarían derechos y obligaciones a nivel internacional, cuyo cumplimiento sería susceptible de ser exigible en forma directa a través de medios de control de la constitucionalidad o de la convencionalidad.

El reconocimiento de la existencia de diversos procesos de creación normativa, entre los cuales se encuentra el soft law,$^{11}$ representa distintas ventajas, entre las cuales se observa el acercar el nacimiento de obligaciones y reconocimiento de derechos a nivel internacional al concepto de "ductilidad" 12 empleado por Zagrebelsky, ${ }^{13}$ en el sentido de que existen normas básicas (como pueden ser los tratados, acuerdos internacionales y el derecho consuetudinario) en las se establecen límites y parámetros que permiten la coexistencia de principios y valores, a través de los cuales puedan proponerse soluciones diversas que reflejen la existencia de sociedades pluralistas y democráticas, en vez de estructuras o fuentes rígidamente ordenadas, en forma piramidal, que pretendan imponer soluciones de arriba hacia abajo, sin tomar en consideración el dinamismo de la evolución social.

Además, visualizar el soft law como un proceso de

\footnotetext{
${ }^{11}$ Sobre todo en el derecho internacional, pero también con incidencia en el derecho interno o doméstico.

${ }^{12}$ La "imagen de ductilidad" que utiliza Zagrebelsky no se refiere en realidad al concepto de soft law sino que deriva de la palabra mitezza del italiano o "dúctil" en su traducción a la lengua castellana, cuyo significado original se utiliza en sentido figurado para indicar que algo o alguien es acomodadizo, dócil o condescendiente, lo cual trasladó a la idea de "ductilidad constitucional" o una "visión abierta" de la Constitución, que permita la coexistencia de los diferentes valores y principios sociales, sin que ninguno de ellos se erija como absoluto y excluyente de los otros, sino que implica una visión inclusiva y de integración a través de una red de valores y procedimientos comunicativos.

${ }^{13}$ ZAGREBELSKY, Gustavo, El derecho dúctil, Madrid, Trotta., 2017, pp.14-20.
}

Revista de Derecho. Vol. 40. No. 1. Año $2019-145$ 
creación normativa permite que, en la elaboración de las normas que dan origen a derechos y obligaciones a nivel internacional, participen diferentes actores, como organismos internacionales, grupos de expertos, organizaciones gubernamentales, etc.

Por todo ello, estimo que el soft law debe ser reconocido y analizado como un proceso de creación normativa, con la definición y características antes apuntadas.

\section{PRINCIPALES INSTRUMENTOS DE SOFT LAW EN EL SISTEMA INTERAMERICANO DE DERECHOS HUMANOS}

El sistema interamericano de protección está compuesto principalmente por dos órganos, la Corte Interamericana de Derechos Humanos (la Corte) y la Comisión Interamericana de Derechos Humanos (la Comisión). Sin embargo, también existen dos órganos políticos que realizan pronunciamientos sobre situaciones concretas o temas que tienen relevancia para la interpretación del derecho interamericano de los derechos humanos, los cuales son la Asamblea General y la Reunión de Consulta de los ministros de relaciones exteriores de los Estados Miembros. ${ }^{14}$

Las competencias de la Corte se establecen en el capítulo VIII de la Convención Americana de Derechos Humanos, siendo las más relevantes (para efectos del presente trabajo) el examen de casos contenciosos y la adopción de opiniones consultivas.

La Corte tiene la competencia jurisdiccional para declarar, en casos donde exista contención entre partes, si un Estado incurrió en responsabilidad internacional por las violaciones a los derechos humanos alegadas en los casos que se pongan a su consideración.

En esta competencia contenciosa puede emitir

\footnotetext{
${ }^{14}$ O'DONELL, Daniel, Derecho Internacional de los Derechos Humanos: normativa, jurisprudencia y doctrina de los Sistemas Universal e Interamericano, México D.F., Oficina en México del Alto Comisionado de las Naciones Unidas para los Derechos Humanos y Tribunal Superior de Justicia del Distrito Federal., 2017, pp.48-55.
}

diversas resoluciones, como son las de medidas provisionales; las de fondo, en las que se pronuncia en relación con las excepciones preliminares, el propio fondo planteado, así como de las medidas de reparación; y las sentencias o resoluciones de supervisión de cumplimiento, en las cuales se analiza precisamente el grado en que se ha acatado la sentencia de fondo y, en su caso, las reparaciones.

Existe un consenso general en que tales resoluciones, emitidas en ejercicio de la competencia contenciosa de la Corte, son fuente de derechos y obligaciones a nivel internacional, no solo para las partes contendientes, sino también para los demás Estados que han reconocido tal competencia, pero existen diferencias de opinión en relación con el grado de vinculación en los casos inter partes y el alcance erga omnes, así como respecto de si es necesario el reconocimiento de los Estados de la jurisdicción contenciosa de la Corte, aspectos a los que se hará referencia más adelante.

Por otra parte, del texto del artículo 64 de la Convención Americana sobre Derechos Humanos ${ }^{15} \mathrm{y}$ de conformidad con su objeto, la función consultiva de la Corte puede definirse como la facultad que tiene ese tribunal para interpretar: a) la Convención Americana; b) todos los tratados que tengan por objeto la protección de los derechos humanos, de los cuales sea parte al menos un Estado americano; c) las disposiciones de tratados internacionales que, a pesar de no tener como objeto general la protección de los derechos humanos, tengan en su contenido referencias a la protección de los derechos humanos y de los cuales sea parte, al menos, un Estado americano, y d)

15. Artículo 64

1. Los Estados Miembros de la Organización podrán consultar a la Corte acerca de la interpretación de esta Convención o de otros tratados concernientes a la protección de los derechos humanos en los Estados Americanos. Asimismo, podrán consultarla, en lo que le compete, los órganos enumerados en el capítulo X de la Carta de la Organización de los Estados Americanos, reformada por el Protocolo de Buenos Aires.

2. La Corte, a solicitud de un Estado Miembro de la Organización, podrá darle opiniones acerca de la compatibilidad entre cualquiera de sus leyes internas y los mencionados instrumentos internacionales. 
la compatibilidad del derecho interno de un Estado americano con alguno o algunos de los anteriores instrumentos internacionales. ${ }^{16}$

En los casos referidos en los incisos a, b y c, la Corte puede ser consultada por cualquiera de los Estados americanos o por alguno o algunos de los órganos del Capítulo X de la Carta de la Organización de Estados Americanos (en el texto reformado por el protocolo de Buenos Aires, firmado el 27 de febrero de 1967$)^{17}$ en el supuesto identificado con el inciso d, la Corte solo puede ser consultada por un Estado miembro de la Organización de Estados Americanos.

En el derecho positivo no existe norma que precise expresamente cuáles son los efectos y alcances de las resoluciones emitidas en el ejercicio de la función consultiva de la Corte, pues el artículo 64 de la Convención Americana sobre Derechos Humanos sólo prevé esa competencia, pero nada dispone en relación con el carácter vinculante o no de tales decisiones; circunstancia que se replica en el Reglamento de la Corte Interamericana de Derechos Humanos, en cuyo Título III, denominado "DE LAS OPINIONES CONSULTIVAS” (artículos 70 a 75) regula diversos aspectos de carácter adjetivo, sin embargo no prevé respecto de la obligatoriedad de las resoluciones respectivas.

En la doctrina el tema respecto del carácter de las resoluciones emitidas en ejercicio de la competencia consultiva tampoco se encuentra resuelto, pues genera posturas encontradas, unas en el sentido de que las opiniones consultivas tienen un carácter no solo vinculante, sino además, erga omnes, aduciendo que, al emitirlas la Corte, son parte de una función meramente jurisdiccional (aunque no exista contención entre partes), además de que, tomando en consideración que la Corte es el intérprete último $\mathrm{y}$ auténtico de la Convención Americana sobre

16 Véase ROA, Jorge Ernesto, La función consultiva de la Corte Interamericana de Derechos Humanos, Colombia, Instituto de Estudios Constitucionales Carlos Restrepo Piedrahita, 2015, pp.34 y ss.

${ }^{17}$ Que son: a) La Asamblea General;b) La Reunión de Consulta de Ministros de Relaciones Exteriores;c) Los Consejos;d) El Comité Jurídico Interamericano;e) La Comisión Interamericana de Derechos Humanos;f) La Secretaría General;g) Las Conferencias Especializadas; y h) Los Organismos Especializados.
Derechos Humanos, sus interpretaciones sobre el "corpus iuris de los derechos humanos" 18 deben ser acatadas por todos los Estados integrantes de la Organización de Estados Americanos (OEA). ${ }^{19}$

Incluso se afirma que el valor de las opiniones consultivas "es comparable a los dictámenes que emanan de la Corte de Justicia de las Comunidades Europeas, y difiere del efecto jurídico que caracteriza a las opiniones consultivas propiamente tales de la Corte Internacional de Justicia”. Además, se hace una distinción entre la consulta que se refiere a la interpretación de la Convención o de otro tratado concerniente a la protección de los derechos humanos(supuesto en el que la resolución correspondiente tendría carácter vinculante) y los casos en que se consulte sobre la compatibilidad de la legislación interna de un Estado con la Convención $\mathrm{u}$ otros tratados concernientes a la protección de los derechos humanos, en el que la Corte sí emitiría una opinión meramente consultiva, pero aun así, la determinación "tendría un efecto jurídico notable, que el Estado no podría ignorar". ${ }^{20}$

Otros posicionamientos señalan que el sistema de opiniones consultivas actual varía del originalmente creado por la Convención Americana sobre Derechos Humanos, con motivo de las diversas reglas establecidas por la propia Corte Interamericana a través de las resoluciones que ha emitido en ejercicio de dicha competencia, lo cual ha originado la existencia de dos "fisuras" consistentes en la indeterminación de los efectos de las opiniones y en la ampliación de la competencia consultiva. Características que impiden que la protección de los derechos humanos se guíe por los estándares establecidos en las decisiones

\footnotetext{
${ }^{18}$ Tal expresión tiene su origen en la resolución a la opinión consultiva OC-16/1999, en la cual se determinó que "El corpus iuris del Derecho Internacional de los Derechos Humanos está formado por un conjunto de instrumentos internacionales de contenido y efectos jurídicos variados (tratados, convenios, resoluciones y declaraciones)".

${ }^{19}$ Como ejemplo de ello véase NIKKEN, Pedro, publicado en " $\mathrm{La}$ función consultiva de la Corte Interamericana de Derechos Humanos", San José, Instituto Interamericano de Derechos Humanos, 1999, pp. 171 a 176.

20 FAÚNDEZ LEDEZMA, Héctor, El Sistema Interamericano de protección de los derechos humanos: aspectos institucionales y procesales, SanJosé, Instituto Interamericano de Derechos Humanos, 2004, $3^{\text {a }}$. Ed., p. 992.
} 
consultivas y relativizan los efectos que deberían tener. Por tanto, es necesario que tales fisuras se subsanen (restringiendo o delimitando claramente la competencia consultiva y estableciendo expresamente el carácter vinculante y efectos de sus resoluciones) con la finalidad de que tales instrumentos dejen de ser vistos como decisiones políticas no vinculantes y constituyan una fuente (directa) de obligaciones internacionales para los Estados. ${ }^{21}$

En mi opinión, ambas posturas sostienen algunos argumentos acertados, pero estimo que aun cuando se considere que las opiniones consultivas no son vinculantes $\mathrm{y}$, por ello, tengan el carácter de soft law, al reconocer que forman parte de un proceso de creación normativa, puede concluirse que, en un primer momento, sí surten determinados efectos jurídicos y, con posterioridad, pueden llegar a ser vinculantes y exigibles.

Por otra parte, la Comisión Interamericana de Derechos Humanos elabora diversos tipos de informes sobre el estado de los derechos humanos en los países miembros de la Organización de Estados Americanos. Además, ha establecido un sistema de relatorías a través de las cuales ha emitido un importante catálogo de principios, por ejemplo, la Declaración de Principios sobre la Libertad de Expresión o los Estándares Jurídicos Vinculados a la Igualdad de Género y a los Derechos de las Mujeres en el Sistema Interamericano: Desarrollo y Aplicación. ${ }^{22}$

También se consideran instrumentos de soft law los documentos emitidos en las reuniones de trabajo de expertos independientes, cuya aplicación tiene limitaciones como consecuencia de la falta de respaldo institucional, pero en diversos casos su empleo se ha generalizado con el paso del tiempo, sobre todo cuando son invocados como opiniones autorizadas por organismos internacionales. Como ejemplo pueden invocarse los Principios de Limburgo

\footnotetext{
${ }^{21}$ Para mayor detalle de esta posición véase ROA, Jorge Ernesto, op. cit. supra, nota 16 .

${ }^{22}$ Documento aprobado por la Comisión Interamericana de Derechos Humanos el 3 de noviembre de 2011 durante su $143^{\circ}$ período ordinario de sesiones. Consultable en la dirección electrónica http://www.oas. org/es/cidh/mujeres/docs/pdf/ESTANDARES\%20JURIDICOS.pdf. Fecha de consulta 11 de abril de 2019.
}

sobre Derechos Sociales, así como los Principios de Johannesburgo sobre la Seguridad Nacional, la Libertad de Expresión y el Acceso a la Información. ${ }^{23}$

Otros instrumentos que se catalogan como soft law son los que derivan de acuerdos entre Estados pero que no fueron concebidos como tratados, sino que habitualmente se les denomina como declaraciones, los cuales tienen el carácter de acuerdos programáticos que ponen de manifiesto la voluntad estatal de actuar en determinado sentido, verbigracia, la Declaración de Río sobre Medio Ambiente y Desarrollo. Sin embargo, los ejemplos más emblemáticos y que, incluso con el paso del tiempo han adquirido un carácter vinculante, son la Declaración Universal de Derechos Humanos y la Declaración Americana sobre Derechos Humanos. ${ }^{24}$

\section{COSA JUZGADA Y COSA INTERPRETADA EN LA COMPETENCIA CONTENCIOSA DE LA CORTE INTERAMERICANA DE DERECHOS HUMANOS}

Como se mencionó en párrafos precedentes, existe un consenso general en que las resoluciones emitidas en ejercicio de la competencia contenciosa de la Corte, son fuente de derechos y obligaciones a nivel internacional, pero su proyección tiene diferentes alcances para las partes que intervinieron en el procedimiento contencioso y para los demás Estados partes de la Convención Americana sobre Derechos Humanos.

De conformidad con los artículos 67 y 68.1 de la Convención, el fallo de la Corte será definitivo e inapelable y los Estados Partes se comprometen a cumplir la decisión en todo caso en que sean partes. En consecuencia, las sentencias adquieren firmeza y eficacia vinculante, por lo que no procede ningún medio de impugnación ni pueden ser revisadas en el ámbito nacional por ninguna autoridad, es decir, alcanzan la entidad de cosa juzgada. ${ }^{25}$

\footnotetext{
${ }^{23}$ CASTRO NOVOA, Luis Manuel, op. cit. supra, nota 5, pp. 72-75.

${ }^{24}$ Ibidem.

25 FERRER MAC-GREGOR, Eduardo, Eficacia de la sentencia interamericana y la cosa juzgadainternacional: vinculación directa hacia las partes(res judicata) e indirecta hacia los Estados partede la convención americana (res interpretata)(Sobre el cumplimiento del
} 
García Ramírez ${ }^{26}$ señala que las decisiones de la Corte en asuntos contenciosos son inmediatamente obligatorias, vinculantes, de forzosa observancia y cumplimiento para los Estados que aceptaron la competencia contenciosa e intervinieron en el proceso respectivo: esto es, poseen eficacia imperativa inter partes. Esta obligatoriedad no suscita dudas, en tanto se halla manifiestamente establecida en la Convención Americana y consta en los actos de aceptación de la competencia contenciosa de la Corte por parte de los Estados.

En su opinión, los criterios establecidos por la Corte al interpretar la Convención (y otros instrumentos con respecto a los cuales dispone de competencia material) son vinculantes para los Estados partes $\mathrm{y}$, con mayor razón, para quienes son sujetos de la jurisdicción contenciosa de la Corte. Sin embargo (señala) esta sujeción no es indispensable para la eficacia vinculante de tales criterios con respecto a dichos Estados.

Su conclusión se basa en la circunstancia de que los Estados partes en la Convención Americana han acogido este instrumento soberanamente, como parte de la preceptiva nacional, asumiendo los deberes que asigna y afrontando los derechos personales que reconoce. $Y$ esos mismos Estados han aceptado que la Corte es el órgano judicial llamado a interpretar las disposiciones convencionales, por lo que establece formal y oficialmente el alcance de tales disposiciones $\mathrm{y}$, en consecuencia, la medida de los deberes de los Estados y los derechos de los particulares.

Por su parte, Ferrer Mc-Gregor ${ }^{27}$ apunta que la sentencia interamericana, en tanto adquiere la autoridad de la cosa juzgada internacional, despliega los contenidos y efectos de la sentencia en dos dimensiones: a) de manera subjetiva y directa hacia las partes en la controversia internacional; y b) de manera objetiva e indirecta hacia todos los Estados Parte en la Convención Americana.

Caso Gelman vs. Uruguay), publicado en Panorámica del derecho procesal constitucional y convencional, Instituto de Investigaciones Jurídicas de la UNAM, 2017, pp.1021-1062.

${ }^{26}$ GARCÍA RAMÍREZ, Sergio, El control judicial interno de convencionalidad, IUS. Revista del Instituto de Ciencias Jurídicas de Puebla A.C., vol. V, núm. 28, diciembre, 2011, pp. 137-139.

${ }^{27}$ FERRER MAC-GREGOR, Eduardo, op. cit. supra, nota 25, p. 1033.
En el primer supuesto se produce una eficacia inter partes, que consiste en la obligación del Estado de cumplir con todo lo establecido en la sentencia interamericana de manera pronta, íntegra y efectiva. De forma que existe una vinculación total y absoluta de los contenidos y efectos del fallo, que se deriva como obligación de los artículos 67 y 68.1 de la Convención Americana.

En el segundo caso se produce una eficacia erga omnes hacia todos los Estados parte de la Convención, en la medida en que todas las autoridades nacionales quedan vinculados a la efectividad convencional $y$, consecuentemente, al criterio interpretativo establecido por la Corte, en tanto estándar mínimo de efectividad de la norma convencional, derivada de la obligación de los Estados de respeto, garantía y adecuación (normativa e interpretativa) que establecen los artículos $1^{\circ}$ y $2^{\circ}$ de la Convención Americana sobre Derechos Humanos.

La eficacia interpretativa erga omnes de la sentencia hacia todos los Estados Parte de la Convención Americana sobre Derechos Humanos, particularmente en aquellos que han aceptado la competencia contenciosa de la Corte, consiste en la obligación por todas las autoridades nacionales (también las jurisdiccionales) de aplicar no sólo la norma convencional (lo cual incluye al corpus iuris interamericano) sino la norma convencional interpretada (res interpretata o cosa interpretada), con lo cual se asegura la efectividad (estándar o mínima) de ese orden normativo de derechos humanos. Ello con base en que es la Corte el intérprete último de ese corpus iuris.

Tal postura también deriva de lo que establecen los artículos 1.1 y 2 de la Convención, en virtud de que existe la obligación de los Estados Parte de respetar y garantizar los derechos y libertades, así como la diversa de adecuación (normativa e interpretativa) para lograr la efectividad de los derechos y libertades cuando no estén garantizados.

En este sentido, no solo existe la obligación estatal de adecuar las normas internas, sino también los 
actos administrativos y jurisdiccionales, de forma que todas las autoridades realicen interpretaciones que no limiten el estándar interpretativo o res interpretata establecido por la Corte, precisamente con la finalidad de respetar el estándar o efectividad mínima de la Convención Americana.

En todo caso, la cosa interpretada tiene un carácter relativo, en el sentido de que las autoridades nacionales pueden válidamente ampliar la eficacia de la norma convencional a través de la interpretación más favorable en aplicación del principio pro personae, que además obliga al Estado debido a lo previsto en el artículo 29.b) de la Convención Americana sobre Derechos Humanos, en la medida en que ninguna disposición de ésta puede ser interpretado en el sentido de que limite el goce y ejercicio de cualquier derecho o libertad que pueda estar reconocido de acuerdo con las leyes de cualquiera de los Estados partes o de acuerdo con otra convención en que sea parte uno de dichos Estados.

Aunado a ello, la res interpretata también puede tener otra limitante, consistente en que se deben considerar las reservas, declaraciones interpretativas $\mathrm{y}$ denuncias que hubiere formulado, en su caso, un Estado.Aunque en esos supuestos la Corte puede analizar la validez de las reservas así como su adecuada interpretación. ${ }^{28}$

De las posturas antes referidas, se aprecia que la eficacia interpretativa de las sentencias de la Corte genera el establecimiento de un estándar mínimo en la determinación del contenido y alcance de los derechos humanos previstos en el corpus iuris interamericano, el cual tiene un carácter erga omnes, es decir, que resulta aplicable a todos los Estados parte de la Convención, independientemente de que se haya reconocido o no la competencia contenciosa de la propia Corte, pues ésta es el intérprete último del Pacto de San José, al cual soberanamente decidieron adherirse todos los contratantes.

Sin embargo, también existen posiciones críticas a los efectos erga omnes de las sentencias de la Corte

\footnotetext{
${ }^{28}$ En la sentencia del caso Radilla Pacheco contra México, se consideró que cuando una reserva suspende todo un derecho fundamental, entonces debe estimarse que su contenido es contrario al objeto y propósito de la Convención.
}

Interamericana de Derechos Humanos, en las cuales se manifiesta que tales efectos generales insisten en un modelo jerárquico de supremacía del derecho internacional sobre el derecho interno, ${ }^{29}$ lo cual, en situaciones extremas, se vuelve difícil de sostener y puede poner en peligro el funcionamiento del propio sistema de control convencional de los derechos humanos.

Además de que da la idea de ausencia de límites en las reglas de competencia para la prevalencia del derecho internacional sobre el interno, lo que suele generar conflictos cuando las controversias incluyen, por ejemplo, aspectos sociológicos o de carácter político.

Pero incluso en tales posturas se acepta que permitir que tribunales nacionales o el derecho interno dejen sin efectos o declaren imposibles de ejecutar decisiones de la Corte Interamericana de Derechos Humanos, generaría situaciones absurdas y nefastas para la protección de derechos. ${ }^{30}$

En mi opinión, la cosa interpretada o eficacia interpretativa de las sentencias de la Corte sí tiene el efecto de fijar un estándar mínimo en la determinación del contenido y alcance de los derechos humanos previstos en el corpus iuris interamericano, además coincido con las posturas que sostienen que éste tiene un carácter erga omnes, pero me parece que ello se encuentra condicionado al reconocimiento de la competencia contenciosa de la propia Corte.

En efecto, si bien los Estados partes de la Convención Americana sobre Derechos Humanos aceptaron su contenido, también debe admitirse que con la finalidad (siempre loable) de avanzar en

\footnotetext{
${ }^{29}$ BANDEIRA GALINDO, George Rodrigo, El valor de la jurisprudencia de la Corte Interamericana de Derechos Humanos, publicado en Protección Multinivel de Derechos Humanos. Manual, Red de Derechos Humanos y Educación Superior, 2013, pp. 255-273.

30 El propio Bandeira Galindo sugiere pensar en modos alternativos de preservar la autoridad de las decisiones de la Corte Interamericana sin imponer al juez interno, por la obligación de realizar el control de convencionalidad, el cumplimiento de toda la jurisprudencia del tribunal internacional. Para ello propone recurrir a la teoría social y a las investigaciones empíricas, para pensar de qué modo se podría establecer un diálogo u otro tipo de conversación entre instituciones internas e internacionales con el fin de acomodar los más diversos intereses y valores.
} 
el desarrollo y protección de los derechos humanos, la Corte ha desarrollado criterios interpretativos que amplían su competencia, tanto desde el punto de vista material (instrumentos respecto de los cuales puede ejercer su labor interpretativa) como subjetiva (sujetos sobre los que ejerce sus funciones y aquéllos a quienes les resultan obligatorias sus resoluciones).

Para que la labor de la Corte como máximo intérprete de la Convención no sea puesta en duda fácilmente, debe apegarse a la voluntad y el contexto en el cual los Estados contratantes se obligaron. Tan es así, que incluso en párrafos precedentes se aprecia como la cosa interpretada también debe tomar en consideración las limitantes consistentes en las reservas, declaraciones interpretativas y denuncias que se hubieren formulado. ${ }^{31}$

En ese orden de ideas, si la cosa interpretada puede tener como limitantes las reservas, declaraciones interpretativas y denuncias que un Estado hubiere formulado, entonces la falta de reconocimiento de la competencia contenciosa de la Corte parece un elemento sine qua non para que los efectos de las exégesis que realiza puedan estimarse como vinculantes y exigibles directamente a ese Estado.

De no respetarse las reglas, voluntades y contexto que dieron origen a la propia Convención Americana sobre Derechos Humanos, especialmente en sus ámbitos competenciales, daría paso a un ambiente de inseguridad jurídica respecto de sus funciones, que fácilmente podría restar legitimidad a su labor.

Por tanto, estimo que la cosa interpretada o eficacia interpretativa de las sentencias de la Corte sí tiene efectos erga omnes para los Estados partes de la Convención que han aceptado la competencia contenciosa de ese tribunal supranacional. Efectividad que se refiere a la mera labor interpretativa, es decir, a la fijación de un estándar mínimo de efectividad de los derechos humanos reconocidos en el Pacto de San José.

\section{ELSOFT LAW Y SU INCORPORACIÓN COMO ESTÁNDAR MÍNIMO DE PROTECCIÓN A}

\footnotetext{
${ }^{31}$ Con la excepción de que su contenido sea contrario al objeto y propósito de la Convención.
}

\section{TRAVÉS DE LA COSA INTERPRETADA}

Como se mencionó en líneas que anteceden, a través del soft law, se establecen principios, reglas, estándares, directrices o comentarios que carecen de carácter vinculante, pero que deben ser reconocidos y analizados como el probable punto de origen de un proceso de creación normativa

En un primer momento, se encuentra la emisión de los instrumentos de soft law, que si bien no tienen un carácter vinculante en sentido estricto, debe destacarse que sí tienen determinados efectos, porque los criterios o estándares que contienen(sobre todo cuando se emiten por un organismo internacional de derechos humanos o cuando se trata de doctrina especializada y altamente reconocida en una materia) adquieren un carácter orientador, respecto del cual, en caso de pretender separarse alguna autoridad de un Estado, tendría que motivar y fundar reforzadamente los preceptos y situaciones de hecho que la llevan a actuar en tal sentido, pues la postura de simplemente ignorarlos aumentará en gran proporción la posibilidad de que se declare su invalidez.

Además, tal fundamentación y motivación reforzada no garantizaría que, cuando se sometieran sus actos a un control de constitucionalidad o de convencionalidad, los juzgadores consideren que con ella se justifica razonablemente apartarse del criterio establecido por la doctrina especializada. Por tanto, se insiste, el solo apartarse de criterio contenido en el soft law, implica una mayor probabilidad de que el acto se declare como inválido.

Ahora, es precisamente a través de esos medios de control que los criterios del derecho flexible pueden conmutar su carácter no vinculante hacia normas, criterios o estándares obligatorios que generarían derechos y obligaciones a nivel internacional, cuyo cumplimiento sería susceptible de ser exigible en forma directa.

En el caso del sistema interamericano, al ser empleado por la Corte en el ejercicio de su 
competencia contenciosa y con motivo de su papel de último y auténtico intérprete del corpus iuris, el criterio contenido en el soft lawadquiere el carácter de estándar mínimo de protección de los derechos humanos, a través de la eficacia interpretativa de sus sentencias o cosa interpretada, con efectos vinculantes y generales o erga omnes para los Estados partes de la Convención que han aceptado la competencia contenciosa de ese tribunal supranacional.

En ese supuesto, la cosa interpretada y sus efectos constituyen la fase final del proceso de creación normativa que tuvo su inicio con la elaboración del instrumento de soft law. Proceso que concreta diversas ventajas, como permitir que, en la elaboración de las normas que dan origen a derechos y obligaciones a nivel internacional, participen diferentes actores, como organismos internacionales, grupos de expertos, organizaciones gubernamentales, etc.

Asimismo, se genera que el nacimiento de obligaciones y reconocimiento de derechos a nivel internacional se acerque al concepto de "ductilidad" empleado por Zagrebelsky, en el sentido de que existen normas básicas (como pueden ser los tratados, acuerdos internacionales y el derecho consuetudinario) en las se establecen límites y parámetros que permiten la coexistencia de principios y valores, a través de los cuales puedan proponerse soluciones diversas que reflejen la existencia de sociedades pluralistas y democráticas, en vez de estructuras o fuentes rígidamente ordenadas, en forma piramidal, que pretendan imponer soluciones de arriba hacia abajo, sin tomar en consideración el dinamismo de la evolución social.

Además, se reconocen y protegen jurídicamente, de forma más rápida y eficaz, la evolución y diversos cambios que sufren constantemente los temas sobre los cuales se pronuncian los instrumentos de derecho blando, sin tener que esperar el largo proceso de negociación y formalización de un convenio internacional.

En otras palabras, bajo el marco estructural de la Convención Americana sobre Derechos
Humanos, así como de las reglas a las cuales se sujeta la competencia contenciosa, puede advertirse la existencia de un proceso de creación normativa, que inicia con la elaboración de principios, reglas, estándares, directrices o comentarios (por parte de organismos internacionales o doctrina altamente especializada y reconocida) y que culmina con su inclusión en la labor interpretativa de las resoluciones de la Corte Interamericana, con lo cual adquieren un carácter vinculantes y general para los Estados que reconocieron tal jurisdicción.

Cabe precisar que la función determinante que lleva a cabo la Corte en tal proceso de creación normativa, debe ejercerse con una gran prudencia, sin incurrir en ampliaciones competenciales de carácter material o subjetivas, para que con ello no exista la posibilidad de generar incertidumbre jurídica, además de impedir la existencia de argumentos que pongan en duda la legitimidad de sus pronunciamientos.

\section{CONCLUSIONES}

1. El soft law y los distintos tópicos que de él surgen, deben analizarse desde una perspectiva de procesos de formación de normas y de creación de derechos y obligaciones internacionales, lo cual permite que las nuevas ideas o valores sociales y el desarrollo de las diversas materias del conocimiento humano (muchas de ellas eminentemente técnicas) encuentren un nuevo ámbito de integración al orden jurídico; así como que esas ideas y valores innovadores y muchas veces contrarios, coexistan a través de soluciones que reflejen la existencia de sociedades pluralistas y democráticas, en vez de estructuras o fuentes rígidamente ordenadas, en forma piramidal, que pretendan imponer soluciones de arriba hacia abajo, sin tomar en consideración el dinamismo de la evolución social.

2. La cosa interpretada o eficacia interpretativa de las sentencias de la Corte Interamericana tiene efectos erga omnes para los Estados partes de la Convención que han aceptado la competencia contenciosa de ese tribunal supranacional. 
Efectividad que se refiere a la mera labor interpretativa, es decir, a la fijación de un estándar mínimo de efectividad de los derechos humanos reconocidos en el Pacto de San José.

3. Existe un proceso de creación normativa en el sistema interamericano de derechos humanos, el cual se sujeta al marco estructural de la Convención Americana, así como a las reglas de la competencia contenciosa, e inicia con la elaboración de principios, reglas, estándares, directrices o comentarios ( por parte de organismos internacionales o doctrina altamente especializada y reconocida) y que culmina con su inclusión en la labor interpretativa de las resoluciones de la Corte Interamericana, con lo cual adquieren el estatus de estándar mínimo de protección, así como un carácter vinculante y general para los Estados que reconocieron tal jurisdicción.

4. La función determinante que lleva a cabo la Corte en tal proceso de creación normativa debe ejercerse con una gran prudencia, sin incurrir en ampliaciones competenciales de carácter material o subjetivas, para que con ello no exista la posibilidad de generar incertidumbre jurídica, además de impedir la existencia de argumentos que pongan en duda la legitimidad de sus pronunciamientos.

\section{BIBLIOGRAFÍA:}

- BANDEIRA GALINDO, George Rodrigo, El valor de la jurisprudencia de la Corte Interamericana de Derechos Humanos, publicado en Protección Multinivel de Derechos Humanos. Manual, Red de Derechos Humanos y Educación Superior, 2013.

- CASTRO NOVOA, Luis Manuel, Fragmentación, soft law y sistema de fuentes del Derecho Internacional de los Derechos Humanos, Bogotá, Universidad Nacional de Colombia, 2014.

- DEL TORO HUERTA, Mauricio Iván, Elfenómeno del soft law y las nuevas perspectivas del Derecho
Internacional, publicado en Anuario Mexicano de Derecho Internacional, vol. VI, 2006.

- FAÚNDEZ LEDEZMA, Héctor, El Sistema Interamericano de protección de los derechos humanos: aspectos institucionales y procesales, San José, Instituto Interamericano de Derechos Humanos, 2004, 3a. Ed.

- FERRER MAC-GREGOR, Eduardo, Eficacia de la sentencia interamericana y la cosa juzgada internacional: vinculación directa hacia las partes (res judicata) e indirecta hacia los Estados parte de la convención americana (res interpretata) (Sobre el cumplimiento del Caso Gelman vs. Uruguay), publicado en Panorámica del derecho procesal constitucional y convencional, Instituto de Investigaciones Jurídicas de la UNAM, 2017.

- GALIANA SAURA, Ángeles, La expansión del Derecho flexible y su incidencia en la producción normativa, publicado en Anuario de Filosofía del Derecho, 2016 (XXXII).

- GARRIDO GÓMEZ, Ma. Isabel, El soft law como fuente del Derecho Extranacional, Madrid, Dykinson, S.L., 2017.

- O’DONELL, Daniel, Derecho Internacional de los Derechos Humanos: normativa, jurisprudencia y doctrina de los Sistemas Universal e Interamericano, México D.F., Oficina en México del Alto Comisionado de las Naciones Unidas para los Derechos Humanos y Tribunal Superior de Justicia del Distrito Federal, 2017.

- ROA, Jorge Ernesto, La función consultiva de la Corte Interamericana de Derechos Humanos, Colombia, Instituto de Estudios Constitucionales Carlos Restrepo Piedrahita, 2015.

- ZAGREBELSKY, Gustavo, El derecho dúctil, Madrid, Trotta., 2017.

\section{HEMEROGRAFÍA:}

Revista de Derecho. Vol. 40. No. 1. Año $2019 \mid-153$ 
- GARCÍA RAMÍREZ, Sergio, El control judicial interno de convencionalidad, publicado en IUS. Revista del Instituto de Ciencias Jurídicas de Puebla A.C., vol. V, núm. 28, diciembre, 2011.

- MAZUELOS BELliDO, Ángeles: "Soft law: ¿mucho ruido y pocas nueces?", publicado en Revista Electrónica de Estudios Internacionales (REEI), No 8, 2004.

\section{DOCUMENTOS DE INTERNET:}

- Declaración de Principios sobre la Libertad de Expresión o los Estándares Jurídicos Vinculados a la Igualdad de Género y a los Derechos de las Mujeres en el Sistema Interamericano: Desarrollo y Aplicación.

- Consultable en la dirección electrónica http:// www.oas.org/es/cidh/mujeres/docs/pdf/ ESTANDARES\%20JURIDICOS.pdf.Fecha de consulta 11 de abril de 2019. 